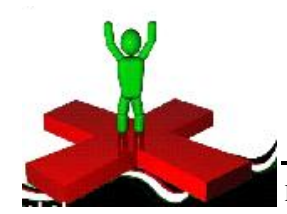

\title{
Health and nutritional status of nursing mother visiting as beneficiaries of anganwadi
}

\author{
DAXA J. JOTANGIYA AND HINA K. BHADANIYA
}

See end of the paper for authors' affiliation

Correspondence to : DAXA J. JOTANGIYA M.V.M. Science and Home Science College, RAJKOT (RAJASTHAN) INDIA

Email:

heena_hs2011@yahoo.in

\begin{abstract}
The Integrated Child Development Services Scheme (ICDS) is India's most ambitious multidimensional welfare programme to reach millions of children and their mothers who are caught in the grip of malnutrition. India is a country suffering from over population, malnourishment, poverty and high infant mortality rates. In order to counter the health and mortality issues gripping the country there is a need for a high number of medical and healthcare experts (Prasanna Kumari, 2006). Researcher to formulate the tool and gave an idea of what items to include in the tool. Data collected with the help of personal interview, filled questionnair and clinical method for haemoglobin estimation. Data was analyzed. More than $83 \%$ mother was 20 to 25 years age at marriage. $92 \%$ were in the age at first child birth of $20-25$ years, $73 \%$ mother haemoglobin level was 9 to $10 \mathrm{~g} \%$ in mother, three year's distance between two children in $64 \%, 12 \%$ mothers had taken need of emergency treatment during Pregnancy Period, 3\% mothers were need to take emergency treatment after the child's birth. Only $11 \%$ children get government help, $67 \%$ mothers prepared premix atta recipes at home, $67 \%$ were used iodized salt in her diet, 5\% mothers have the knowledge of nutrition, 5\% mothers have the knowledge of balance diet, $17 \%$ mothers washed Veg. /fruits before use, $100 \%$ mothers covered the Food .On the whole the researcher concluded that the nursing mother who were visited anganwadi regularly benefited the most.
\end{abstract}

How to cite this paper : Jotangiya, Daxa J. and Bhadaniya, Hina K. (2014). Health and nutritional status of nursing mother visiting as beneficiaries of anganwadi. Internat. J. Med. Sci., 7(1\&2) : 33-37.

\section{KEY WORDS :}

Nursing mother, Haemoglobin, Nutrition, Health, Anganwadi 